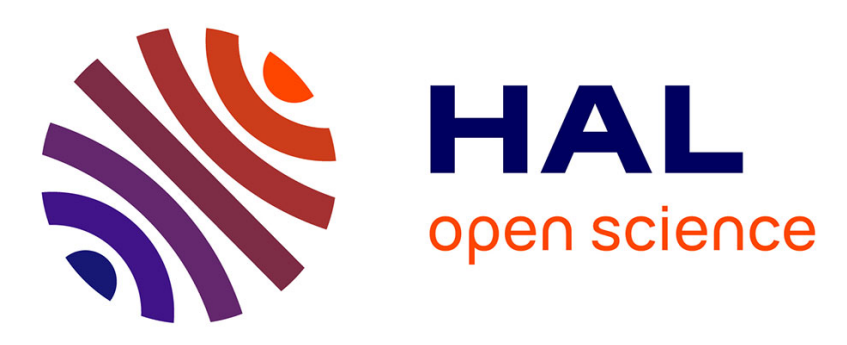

\title{
Shade and drought growth conditions strongly impact dynamic responses of stomata to variations in irradiance in Nicotiana tabacum
}

Théo Gerardin, Cyril Douthe, Jaume Flexas, Oliver Brendel

\section{- To cite this version:}

Théo Gerardin, Cyril Douthe, Jaume Flexas, Oliver Brendel. Shade and drought growth conditions strongly impact dynamic responses of stomata to variations in irradiance in Nicotiana tabacum. Environmental and Experimental Botany, 2018, 153, pp.188-197. 10.1016/j.envexpbot.2018.05.019 . hal-01891743

\author{
HAL Id: hal-01891743 \\ https://hal.science/hal-01891743
}

Submitted on 9 Oct 2018

HAL is a multi-disciplinary open access archive for the deposit and dissemination of scientific research documents, whether they are published or not. The documents may come from teaching and research institutions in France or abroad, or from public or private research centers.
L'archive ouverte pluridisciplinaire HAL, est destinée au dépôt et à la diffusion de documents scientifiques de niveau recherche, publiés ou non, émanant des établissements d'enseignement et de recherche français ou étrangers, des laboratoires publics ou privés. 


\section{Published in}

2Article title: Shade and drought growth conditions strongly impact dynamic responses of 3stomata to variations in irradiance in Nicotiana tabacum

4Article reference: EEB3456

5Journal title: Environmental and Experimental Botany

6Corresponding author: Dr Oliver Brendel

7First author: Mr Theo Gerardin

8Accepted manuscript available online: 28-MAY-2018

9DOI information: 10.1016/j.envexpbot.2018.05.019

10https://doi.org/10.1016/j.envexpbot.2018.05.019

11

12Authors: Théo Gerardin ${ }^{1,2}$, Cyril Douthe², Jaume Flexas², Oliver Brendel ${ }^{1,3}$

13

14Adresses:

$15^{1}$ Université de Lorraine, AgroParisTech, INRA, Silva, F-54000 Nancy, France

$16^{2}$ Research Group on Plant Biology under Mediterranean Conditions, Universitat de les Illes Balears, Instituto 17de Investigaciones Agroambientales y de Economía del Agua (INAGEA), Carretera de Valldemossa Km 7.5, 18Palma de Mallorca, Illes Balears 07121, Spain

$19^{3}$ Corresponding author postal address: Oliver BRENDEL, INRA, UMR Silva, F-54280 CHAMPENOUX, 20France

21Tel : 0033.383394100

22Emails:

23theo.gerardin@inra.fr, cyrildouthe@me.com, jaume.flexas@uib.es, oliver.brendel@inra.fr

24Keywords: drought, dynamic response, irradiance, shade, stomatal conductance

25

26 


\section{Abstract}

28Recent research has made progress in describing stomatal dynamics in terms of speed, amplitude of 29response, lag time and response time. However, little is known about the impact of growth 30 conditions on the rapidity of stomatal movements, and their relationship with stomatal morphology 31within a species. We measured stomatal dynamics during opening and closing in response to 32 changes in irradiance in tobacco plants (Nicotiana tabacum) grown under "Control", "Drought" and 33 "Shade" treatments. Growth conditions strongly changed the rapidity of stomatal responses to 34irradiance. The "Drought" treatment considerably accelerated the response and "Shade" treatment 35slowed it down when compared to "Control". We confirmed for the "Control" treatment the known 36asymmetry of response, with closing faster than opening, but interestingly the asymmetry 37disappeared under both treatments. Only stomatal density and index were affected by the growth 38 conditions, not stomatal size and form. Thus, the observed variation in stomatal closing and opening 39dynamic parameters (speed, amplitude, lag time, response time) was not due to a variation in the 40size of the stomata, and only a marginal relationship between speed of the stomatal response and 41stomatal density was observed. These results suggest that physiological factors might be the main 42driver of variations in stomatal conductance dynamics within a species grown under different 43environmental conditions.

\section{Highlights}

46 - Growth conditions (drought/shade) change dynamics of stomatal response to irradiance

47 - Growth conditions change stomatal dynamics between lag and response times

48 - Growth conditions (drought/shade) change asymmetry between opening and closing

- Within species variation in stomatal speeds were not explained by stomatal size 


\section{Introduction}

51Stomatal morphology and their movements (opening and closing) are key components controlling 52exchange of water vapour and $\mathrm{CO}_{2}$ between the leaf and the atmosphere, expressed as stomatal 53conductance $\left(\mathrm{g}_{\mathrm{s}}\right)$. Stomatal conductance per leaf surface is mainly determined by stomatal density, 54size, pore area (aperture) and their distribution. Since plants are subjected to a fluctuating 55environment through a diurnal cycle, with important variations of irradiance, vapour pressure deficit 56between the leaf and the atmosphere (VPD), temperature and soil water deficit, they need to balance 57gas exchange by adjusting stomatal conductance continuously during the day (Schulze and Hall, 581992; Pearcy et al., 2000). Usually stomata respond to low $\mathrm{CO}_{2}$, low VPD and high irradiance by 59increasing their level of aperture, inducing an increase of $g_{s}$ and vice versa (Outlaw, 2003). $60 \mathrm{Nevertheless,} \mathrm{these} \mathrm{environmental} \mathrm{changes} \mathrm{usually} \mathrm{occur} \mathrm{concomitantly,} \mathrm{making} \mathrm{g}_{\mathrm{s}}$ a complex 61resultant of various signals which are induced via different signalling pathways and treated 62hierarchically (Lawson and Morison 2004; Lawson et al., 2010; Aasamaa and Sober, 2011; 63Haworth et al., 2018).

64To describe the stomatal behaviour, numerous steady-state models of $\mathrm{g}_{\mathrm{s}}$ have been proposed 65(reviewed in Damour et al., 2010). However $\mathrm{g}_{\mathrm{s}}$ variations induced by environmental changes are not 66instantaneous and show a temporal response that can be described by dynamic models (Vialet67Chabrand et al., 2017). Changes in stomatal aperture result from variations of water content of the 68guard cells, which are in turn produced by fluxes of potassium ions $\left(\mathrm{K}^{+}\right)$in or out of the guard cell 69(Blatt, 2000; Shimazaki et al. 2007). Kirschbaum et al. (1988) proposed a temporal model where the 70dynamic response of $g_{s}$ to irradiance was first initiated by a biochemical signal responding to the 71environmental change, followed by an osmotic adjustment inside the guard cells resulting in 72stomatal opening. The combination of these processes described the response of $g_{s}$ as a sigmoidal 73curve. The dynamic change of $g_{s}$ to atmospheric environmental variations takes from a few minutes 74to almost an hour, depending on species and irradiance variation (Vico et al., 2011; McAusland et 75al., 2016). Compared to stomatal dynamics in response to changes in irradiance, the variation of net $76 \mathrm{CO}_{2}$ assimilation $\left(A_{\mathrm{n}}\right)$, if not limited by $\mathrm{g}_{\mathrm{s}}$, varies much faster, usually within a few seconds. Several 77studies highlighted the importance of photosynthetic response times for carbon uptake (reviewed in 78Kaiser et al., 2018), however as these are generally an order of magnitude faster than changes in $\mathrm{g}_{\mathrm{s}}$, 79variation in the latter might be dominant in non-synchronicity situations.

80Irradiance is the main environmental driver of photosynthesis, therefore the stomatal response to 81fluctuating light has been extensively studied (Kirschbaum et al., 1988 ; Shimazaki et al., 2007 ; 82Lawson et al., 2010 ; McAusland et al., 2016 ; Kardiman and Raebild, 2017 ; Matthews et al., 832018). Over time these fluctuations drive the temporal dynamics of carbon gain, water loss and by 
84extension the water use efficiency of the plant (Lawson and Blatt, 2014). Stable environmental 85 conditions rarely occur in nature, therefore field measurements of $\mathrm{g}_{\mathrm{s}}$ are unlikely to reach steady86states values (Lawson et al., 2010) resulting in decoupled $A_{n}$ and $\mathrm{g}_{\mathrm{s}}$ measures and a non87representative estimation of the ratio of $A_{n}$ to $g_{s}$, the intrinsic water use efficiency (Lawson et al., 882010; McAusland et al., 2016, Vialet-Chabrand et al. 2017). A non-synchronicity in the temporal 89response between $A_{\mathrm{n}}$ and $\mathrm{g}_{\mathrm{s}}$ can have repercussions on carbon fixation, the water lost by 90transpiration and long-term water use efficiency (McAusland et al., 2016). Due to the importance of 91dynamic stomatal regulation, modelling of $g_{s}$ responses to environmental changes can improve the 92up-scaling of $\mathrm{CO}_{2}$ and water vapour exchange from the leaf to the canopy level (Vialet-Chabrand et 93al., 2017). To parametrize such models, it is important to gain knowledge on the impact of growth 94conditions on the stomatal dynamics.

95Morphological traits such as stomatal density and size regulate steady-state values of $\mathrm{g}_{\mathrm{s}}$ (Franks and 96Farquhar, 2001) and set the theoretically achievable maximum stomatal conductance by the plant 97(Dow et al., 2014). A variation in stomatal morphology can lead to improved instantaneous and 98long-term water use efficiency by impacting directly only $g_{s}$, but not A (Doheny et al., 2012; Franks 99et al., 2015). It has also been shown that an increase in $\mathrm{g}_{\mathrm{s}}$ under high irradiance conditions was 100associated to an increase of stomatal density (Schlüter et al., 2003). Stomatal morphology and 101patterning is known to be influenced by both environmental growth conditions and plant hormones 102(Woodward, 1987; Hetherington and Woodward, 2003; Casson and Gray, 2008; Kardiman and 103Raebild, 2017). In tobacco leaves, Thomas et al. (2004) observed a 12.7-24.2\% decrease of stomatal 104index (ratio between number of stomata to total number of stomatal and epidermal cells) of 105developing leaves exposed to shading compared to a control treatment. Although growth conditions 106varying in atmospheric $\mathrm{CO}_{2}$ concentration and irradiance have been shown to impact stomatal 107morphology, little is known about other environmental factors such as soil water stress. Jones 108(1977) showed for barley that a reduction of soil water availability could result in a decrease in 109stomatal index, but this is not always consistent as reported for groundnut (Clifford et al., 1995), 110where the stomatal index was not changed by water stress.

111It has been hypothesized (Hetherington and Woodward, 2003; Drake et al. 2013, Raven, 2014; 112Kardiman and Raebild 2017) that stomatal traits such has density and size might be involved in the 113temporal response of $g_{s}$ to an environmental change. These studies, based mainly on among species 114comparisons, suggested that a smaller stomatal size resulted in a faster stomatal response due to the 115higher surface-to-volume ratio and the lower subsequent solute transport required to drive stomatal 116movements (Lawson et al., 2014). Other recent evidence using a very large spectrum of species, 117including ferns, cycads, conifers, and angiosperms (Elliot-Kingston et al., 2016) had not found a 
118relationship between stomatal size and closing speed, however the authors suggest a relationship 119 with the atmospheric $\mathrm{CO}_{2}$ levels during species diversification. Moreover, variations in stomatal 120size are often negatively correlated to variations in stomatal density (Franks and Beerling, 2009; 121Doheny-Adam et al., 2012). Also, the relationship between stomatal response times and the shape 122of the guard cells (Hetherington and Woodwaard, 2003; Franks and Farquhar, 2007; McAusland et 123al., 2016) and their patterning (Papanatsiou et al., 2016) have been studied. It has been shown that 124the stomatal shape (dumbbell or elliptical) might be a determinant driver of stomatal speed as 125dumbbell-shaped guard cells species tend to display faster responses to environmental fluctuations 126(Hetherington and Woodwaard, 2003; MacAusland et al., 2016). Moreover, the stomatal shape and 127patterning might confer different mechanical advantages via cell osmotic and turgor pressures 128influencing the rapidity of stomatal response (Franks and Farquhar, 2007). However, other 129parameters than stomatal morphology, such as variations in ion and water transport within guard 130cells, are likely to impact the speed of stomatal responses (Lawson and Blatt, 2014).

131 Growth conditions such as shade and soil water deficit have been shown to determine steady state 132stomatal conductance, however, only a few studies examined their influence on stomatal dynamics. 133In these studies, drier conditions have been related to faster stomatal response to irradiance (Vico et 134al., 2011; Lawson and Blatt., 2014; Qu et al., 2016) suggesting an influence of plant water balance 135on the rapidity of the stomatal response. Martins et al. (2016) demonstrated in conifers and ferns a 136major impact of leaf hydraulic status on $\mathrm{g}_{\mathrm{s}}$ response time to variations in vapour pressure deficit. 137Less is known about the impact of different light environments during growth on the dynamics of 138stomatal responses to a change in irradiance. Matthew et al. (2018) have shown faster stomatal 139responses with an increased amplitude for Arabidopsis thaliana grown under fluctuating high light, 140compared to plants grown under shaded conditions. Kardiman and Raebild (2017) showed that, 141although the dynamics of stomata of most tested species remained unaffected by their light 142environment, early successional species displayed faster stomatal responses when grown under 143shade conditions compared to the ones grown under full light, while late successional species 144displayed the opposite behaviour. These results could suggest that the acclimation of stomatal 145dynamics to the light environment might be species specific and related to their ecology.

146Differences in the speed of stomatal dynamics to a variation in irradiance have been shown among 147species and within individuals of the same species (Vico et al., 2011; McAusland et al., 2016). 148Stomatal speed has also been linked to plant functional types and environmental factors (Vico et al., 1492011): graminoids tended to display shorter responses than forbs, woody gymnosperms or 150angiosperms and plants from dryer climates seemed to exhibit faster responses. Moreover, many 151species show an asymmetric response between stomatal opening and closing, ie, over $60 \%$ of the 
152species reviewed by Ooba and Takahashi (2003) displayed a faster opening. Ooba and Takahashi 153(2003) argued that such an asymmetry could be related to the environmental growth conditions of 154the different species, where a light limited environment might favour a more rapid opening of 155stomata. However, Woods and Turner (1971) have suggested that a faster stomatal closure would 156reduce the temporal decoupling between $A_{n}$ and $\mathrm{g}_{\mathrm{s}}$ while a slower opening would reduce water loss 157without reducing $A_{n}$ when $\mathrm{g}_{\mathrm{s}}$ is not limiting, especially under well-watered conditions. Such a 158temporal asymmetry of stomatal movements might lead to a reduced transpiration and thus translate 159a conservative stomatal behaviour. Moreover, a slow opening might prevent situations of a 160continued $\mathrm{g}_{\mathrm{s}}$ increase after $A_{n}$ has reached light saturation, which would result in an excessive water 161loss compared to carbon gain (Kirschbaum et al., 1988; Lawson et al., 2010; Vialet-Chabrand et al., 1622017). The literature therefore suggests that the asymmetry between opening and closing of stomata 163might have an important ecological impact, depending on the growth conditions.

165Thus, our main objectives were to analyse:

166 (i) the impact of three different growth conditions (control, shade and drought) on the 167 parameters conditioning the temporal response of $g_{s}$ to step variations in irradiance;

168 (ii) the relationship between stomatal morphology and the dynamics of stomatal responses

169The dynamics of the temporal stomatal response to a step variation in irradiance was characterised 170by a model based on Vialet-Chabrand et al. (2013), which decomposes the sigmoidal response into 171a) the delay of stomatal response, b) the response time constant and c) the amplitude of stomatal 172movements. From the latter two parameters a maximal speed can be calculated. The stomatal 173response has been tested for opening and closing, which allowed also to estimate the asymmetry for 174the dynamic parameters. 


\section{Material and methods}

\subsection{Plant material and Experimental design}

177The experiment lasted for 8 weeks and was carried out on eighteen plants of Nicotiana tabaccum L. 178wild type (cv. Petite Havana SR1), grown at the University of the Balearic Island (UIB), Palma, 179Spain, 39³8'11.9"N 2०38'49.7"E in autumn 2015. Seeds were germinated in petri boxes with 180humidified filter paper and after one week transferred into $2 \mathrm{~L}$ pots filled with $1 / 3(\mathrm{~V} / \mathrm{V})$ of perlite 181and organic soil, respectively.

182The two weeks old seedlings were then randomly divided into the three treatments: "Control" (6 183plants), "Shade" (7 plants) and "Drought" (5 plants). The "Control" treatment was characterized by 184ambient growth irradiance (400-450 $\mu \mathrm{mol}$ photons $\mathrm{m}^{-2} \mathrm{~s}^{-1}$ ) and well-watered conditions. The 185 "Shade" treatment was characterized by low irradiance ( $40 \mu \mathrm{mol}$ photons $\left.\mathrm{m}^{-2} \mathrm{~s}^{-1}\right)$ and the same well186watered conditions as in the "Control" treatment. The irradiance compensation point, estimated 187 from steady-state irradiance response curves (data not shown) were estimated at $30 \mu \mathrm{mol} \mathrm{m}^{-2} \mathrm{~s}^{-1}$ for 188"Control" and $27 \mu \mathrm{mol} \mathrm{m} \mathrm{m}^{-2} \mathrm{~s}^{-1}$ for "Shade" treatments; 90\% of maximum A was reached at about

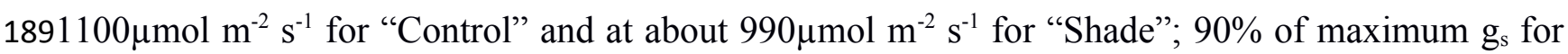
190"Shade" was reached at $500 \mu \mathrm{mol} \mathrm{m} \mathrm{m}^{-2} \mathrm{~s}^{-1}$. Plants in "Control" and "Shade" treatments were watered 191every second day with Hoagland's solution, 50\% dilution. The "Drought" treatment was 192characterized by the same ambient growth irradiance as the "Control" treatment, but the plants were 193submitted to a soil water deficit. The water deficit was controlled by weighing the pots at field 194 capacity and watering to $50 \%$ of the weight. During the experiment the field capacity weight was 195verified on the plants of the "Control" treatment on a regular basis and the difference assumed to be 196the plant growth and added to the target weights of the "Drought" treatment. Before application of 197the treatments, the last emergent leaf was marked to ensure gas exchange measurement were done 1980n leaves grown under treatment conditions. Other conditions in the growing chamber were $25^{\circ} \mathrm{C}$, 199air relative humidity 50-60\% and a photoperiod of $12 \mathrm{~h} / 12 \mathrm{~h}(8: 00-20: 00)$.

\subsection{Measurement of leaf water potential}

201To determine the plant water status, midday leaf water potential ( $\Psi$ ) was measured in fully 202expanded leaves with a Scholander pressure chamber (Soil moisture Equipment Corp., Santa 203Barbara, CA, USA). At the end of the experiment, that is six weeks after separating the plants into 204the treatments, six leaves were measured for the control treatment from different plants and 4 leaves 205 for each, the shade and the drought treatment. 
207Gas exchange was measured using a portable photosynthesis system (LI-COR 6400; LI-COR, 208Lincoln, NE, USA) equipped with a $2 \mathrm{~cm}^{2}$ leaf chamber (Li-6400-40). Measured were: net $\mathrm{CO}_{2}$ 209assimilation rate $\left(A_{\mathrm{n}}\right)$, stomatal conductance for water vapour $\left(\mathrm{g}_{\mathrm{s}}\right)$ and leaf internal $\mathrm{CO}_{2}$ 210concentration $\left(\mathrm{C}_{\mathrm{i}}\right)$ (see Table 1 for units). All measurements were carried out between 10:00 and 21119:00 h (Central European summer time). For each plant measured, gas exchange measurements 212 were performed on the youngest, mature, fully expanded leaf, which had grown under treatment 213conditions. This leaf has been measured three times at different days and different times during the 214day. Overall, the measurement of all stomatal response curves has taken 18 days. The 215environmental parameters inside the chamber were kept constant during the acclimation phase with $216\left[\mathrm{CO}_{2}\right]$ entering the chamber of $400 \mu \mathrm{mol} \mathrm{mol}{ }^{-1}$, block temperature of $25^{\circ} \mathrm{C}$, air flow of $300 \mu \mathrm{mol}$ $217 \mathrm{~min}^{-1}$ and a PPFD of $1500 \mu \mathrm{mol} \mathrm{m} \mathrm{m}^{-2} \mathrm{~s}^{-1}$ (red/blue irradiance 90/10\%, respectively) until the leaf 218reached a steady-state of $g_{s}(\mathrm{SS} 1$; Fig. 1a). Then a measurement cycle consisted of two step-changes 219in irradiance: first I) a single step-change to low irradiance inducing stomatal closure and then II) a 220 single step-change back to the original high irradiance, inducing a stomatal reopening. For the low 221irradiance step, the PPFD was lowered from 1500 to $100 \mu \mathrm{mol} . \mathrm{m}^{-2} \mathrm{~s}^{-1}$ until the plant reached a new 222steady-state (SS2). After 10 minutes under this new steady-state, the PPFD was set back to its initial 223setting at $1500 \mu \mathrm{mol} . \mathrm{m}^{-2} \mathrm{~s}^{-1}$ and measurements were recorded until a new steady state was reached 224(SS3). The stomata were considered in steady-state when $\mathrm{g}_{\mathrm{s}}$ did not vary more than $\sim 0.005 \mathrm{~mol} \mathrm{~m}^{-2}$ $225 \mathrm{~s}^{-1}$ during $10 \mathrm{~min}$. This resulted in a standard deviation over the 10 minutes of $0.0015 \mathrm{~mol} \mathrm{~m}^{-2} \mathrm{~s}^{-1}$. 226Data during the response curves were logged every 60sec. "Steady-state" data as mentioned through 227the manuscript were calculated for SS1, SS2 and SS3 as the mean of 5 points after stabilization of $228 g_{s}$, (Fig. 1a). 

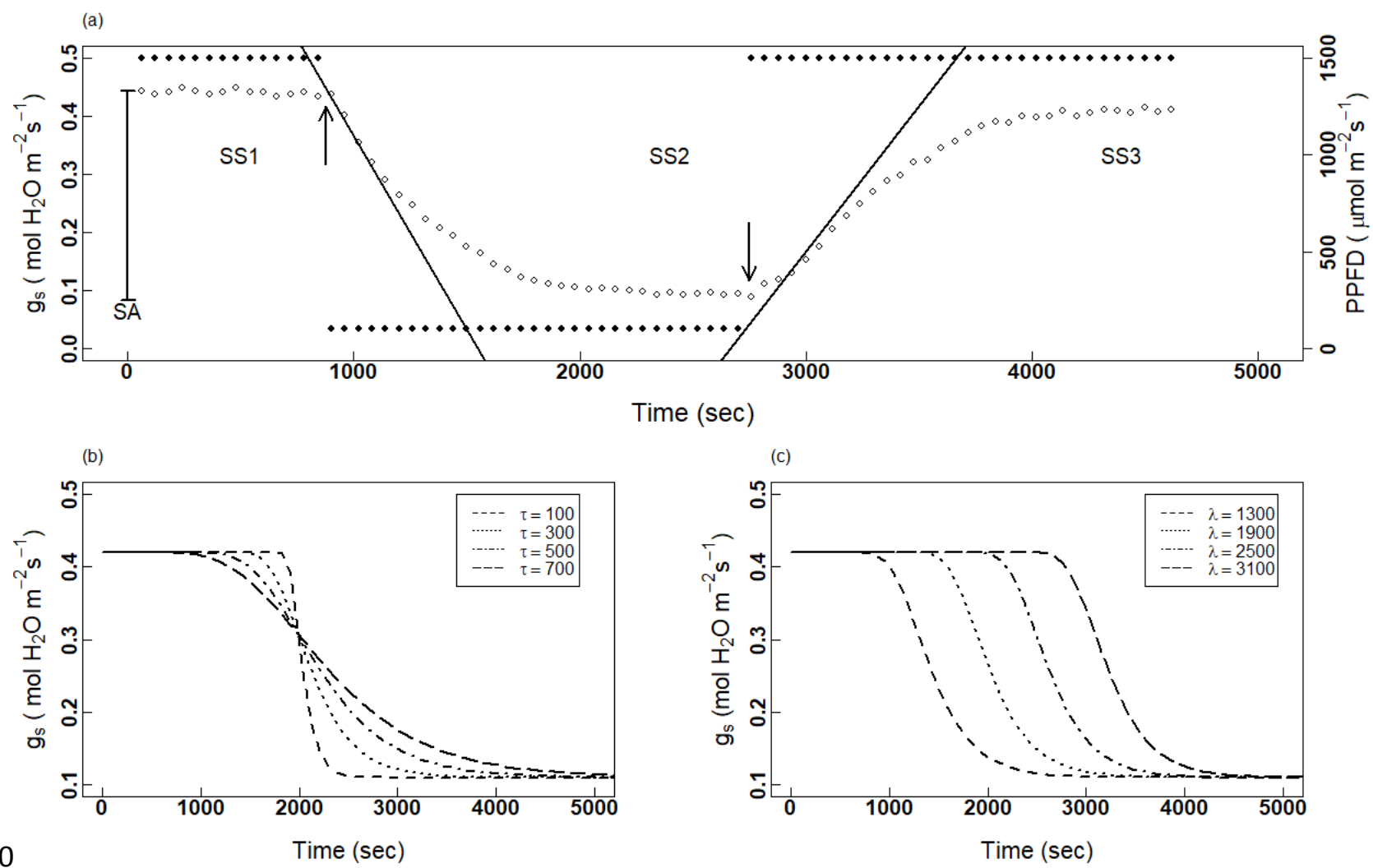

231Figure 1: Illustration of the stomatal dynamics for irradiance step-changes. a: Example of a 232measured stomatal closure and opening (white dots) provoked by a change in irradiance (black 233dots). Black arrows represent the irradiance changes, the black lines are the maximal slopes $\left(\mathrm{SL}_{\max }\right)$ 234of both opening and closing sequences and the amplitude of the stomatal response (SA). b: 235Simulation of the impact of increasing values by 200secs steps of $\tau$ (response time) on the 236curvature of the sigmoidal model, and c: Simulation of the impact of 600secs steps increasing 237 values of $\lambda$ (lag time) on the stomatal delay.

\subsection{Stomata morphology}

240At the end of the experiment one leaf was sampled from each of five plants per treatment to 241determine the stomatal morphology of leaves on the abaxial and adaxial faces. Specifically, the 242following parameters were measured : the stomatal density (SD), epidermal cell density (CD), 243stomatal index (SI) defined as $\mathrm{SD} /(\mathrm{SD}+\mathrm{CD})$, length of the stomatal guard cell complex (GCL), 244guard cells width (GCW), stomatal surface (SS) defined as an ellipse area: $\pi^{*}(\mathrm{GCL} / 2)^{*}(\mathrm{GCW} / 2)$ 245and guard cell shape (GSH) defined as the ratio GCL/GCW. $1 \mathrm{~cm}^{2}$ portions of the leaves were 246 collected and nail polish imprints of both leaf surfaces were taken using adhesive film and applied 247on microscope slides for analysis. Stomata and epidermis cells were counted in the obtained images 
248using the ImageJ2 software (Schindelin et al. 2015). Six images $(500 * 370 \mu \mathrm{m})$ of the abaxial and 249adaxial surfaces of the leaf used for gaz exchange were taken.

\subsection{Model description}

251The stomatal responses of the irradiance curves were adjusted using a sigmoidal model based on 252Vialet-Chabrand et al. (2013). The sigmoidal model allows the estimation of parameters describing 253the temporal response of the stomata to an environmental change. The following equation was used:

$254 g s=r 0+(G-r 0) * \exp \left(-\exp \left(\frac{\lambda-t}{\tau}\right)\right)$

255 where $g_{s}$ is the fitted stomatal conductance, $r 0$ is the starting value of the stomatal conductance (first 256steady-state obtained after the plant acclimation to the environmental conditions inside the Licor 257chamber, $g_{\min }$ or $g_{\max }$ ), $G$ the ending value of stomatal conductance (second steady-state reached 258after the full stomatal response to the irradiance change, $g_{\max }$ or $\left.g_{\min }\right), \lambda$ is the lag time of the 259stomatal response (time needed to reach the inflection point of the curve from the moment of the 260irradiance change in each curve), and $\tau$ the response time. Compared to the sigmoidal equation used 261by Vialet-Chabrand et al. (2013), here, $\lambda$ is mathematically independent from $\tau$ (see Fig. $1 \mathrm{~b}$ and c). 262From these parameters, the maximum slope $\left(\mathrm{SL}_{\max }\right)$ as estimator of the speed of the stomatal 263response, can be calculated as:

264SLmax $=(1 / \tau) *(G-r 0) / e$

265Where (G-r0) represents the amplitude of the stomatal response (SA) and e the Euler constant. 266Increasing values of $\tau$ will affect the curvature of the stomatal response, the smaller a $\tau$ value is, the 267stronger the curvature (Fig. $1 \mathrm{~b}$ ) and the higher $\mathrm{SL}_{\max }$ will be, so the more rapidly $\mathrm{g}_{\mathrm{s}}$ will 268increase/decrease.

269This model was adjusted using the function "nlminb" of $\mathrm{R}$ (Team RC, 2015). To facilitate the 270adjustment of the sigmoidal model, five data points during the steady state before changing the 271irradiance were first included in the model adjustment. This affects only the lag time $\lambda$, which was 272then corrected by subtracting the added time period. The model adjustment is sensitive to the 273starting point and including five steady state points made the starting steady state $g_{s}$ more robust and 274 decreases the dependency of the adjustment on measurement noise.

275As SS1 and SS3 values for all gas exchange variables were not significantly different (pairwise t276test $\mathrm{p}>0.05)$ the mean amplitude between closing and opening in response to the step-change in 277irradiance were calculated for $A_{n}$ and $\mathrm{g}_{\mathrm{s}}$ as absolute and relative values (SA and RSA, respectively; 278Table 1) : 
$279 \mathrm{SA}_{A n}=((A n \mathrm{SS} 1-A n \mathrm{SS} 2)+(A n \mathrm{SS} 3-A n \mathrm{SS} 2)) / 2$

$280 \mathrm{SA}_{g s}=\left(\left(\mathrm{g}_{\mathrm{s}} \mathrm{SS} 1-\mathrm{g}_{\mathrm{s}} \mathrm{SS} 2\right)+\left(\mathrm{g}_{\mathrm{s}} \mathrm{SS} 3-\mathrm{g}_{\mathrm{s}} \mathrm{SS} 2\right)\right) / 2$

$281 \mathrm{RSA}_{A n}=(((A n \mathrm{SS} 1-A n \mathrm{SS} 2) / A n \mathrm{SS} 1)+((A n \mathrm{SS} 3-A n \mathrm{SS} 2) / A n \mathrm{SS} 3)) / 2 * 100 \%$

$282 \mathrm{RSA}_{g s}=\left(\left(\left(\mathrm{g}_{\mathrm{s}} \mathrm{SS} 1-\mathrm{g}_{\mathrm{s}} \mathrm{SS} 2\right) / \mathrm{g}_{\mathrm{s}} \mathrm{SS} 1\right)+\left(\left(\mathrm{g}_{\mathrm{s}} \mathrm{SS} 3-\mathrm{g}_{\mathrm{s}} \mathrm{SS} 2\right) / \mathrm{g}_{\mathrm{s}} \mathrm{SS} 3\right)\right) / 2 * 100 \%$

283For the adjusted dynamic parameters, we also calculated the ratio between closing and opening, 284representing the asymmetry of the response. Further, the ratio between $\tau$ and $\lambda$ was calculated, to 285 characterise the relative impact of different treatments on both parameters.

\section{6}

2872.6 Statistical analysis

288All statistical analyses were performed with R (Team RC, 2015). Treatment effects were analysed 289as a one factorial design analysis of variance (ANOVA). Significant differences were considered at $290 \mathrm{p}<0.05$. When the ANOVA showed a significant treatment effect, a Post-Hoc test using Tukey291HSD (package R, "agricolae") was used to estimate significance of inter-group differences. 292Comparisons among steady-state gas exchange variables as well as of closing versus opening were 293done using pairwise t-tests. For all stomatal morphology traits, mean values of all images taken on 294the adaxial and abaxial surfaces were used for ANOVA and correlations with gas exchange results 295were based on a mean of the 3 repetitions per leaf. Correlations were estimated using the Pearson 296method and p-values were adjusted for multiple comparisons using the "p.adjust" function with the 297"FDR" method. 


\section{Results}

\subsection{Steady-state gas exchange parameters under three different growth conditions}

300The different growth conditions significantly affected $\Psi$ of tobacco plants, with the highest value 301for the "Shade" treatment $(-0.37 \pm 0.06 \mathrm{Mpa})$, without being significantly different from the 302 "Control" treatment $(-0.51 \pm 0.09 \mathrm{Mpa}, \mathrm{p}>0.05$ TukeyHSD), while the "Drought" treatment 303significantly decreased $\Psi$ to $-1.46 \pm 0.18 \mathrm{Mpa}$ ( $\mathrm{p}>0.05$ TukeyHSD). $A_{\mathrm{n}}$ values measured under 304saturating irradiance (SS1, see Fig. 1) were significantly different among treatments, where the 305 "Control" treatment showed the highest value and "Shade" the lowest (Table 1). g values differed 306among the treatments, showing the highest values in "Control" and the lowest in "Drought". These 307strong differences for $A_{\mathrm{n}}$ and $\mathrm{g}_{\mathrm{s}}$ were associated with significantly different $\mathrm{C}_{\mathrm{i}}$ among treatments, 308with the highest $C_{i}$ in the "Shade" and the lowest under "Drought". Decreasing irradiance from high 309to low intensity (SS1 to SS2, see Fig. 1), $A_{\mathrm{n}}$ and $\mathrm{g}_{\mathrm{s}}$ decreased drastically as expected (Table 1), but 310not $\mathrm{C}_{\mathrm{i}}$, for which no significant differences were detected among the three steady-states, within each 311treatment.

\subsection{Amplitude of response under changing measuring irradiance}

313For both $A_{n}$ and $\mathrm{g}_{\mathrm{s}}$, their respective variations were similar during closing and opening as there was 314no significant difference between the two high-irradiance steady state measurements (SS1 and SS3; 315pairwise t-test $\mathrm{p}>0.05$ ) indicating a full reopening, therefore the analysis of the absolute and 316relative amplitude of the responses (SA and RSA (\%), respectively) was based on the mean values 317of closing and opening sequences (presented in Table 1). The absolute amplitude of the A response $318\left(\mathrm{SA}_{A \mathrm{n}}\right)$ was highest for "Control" and lowest for "Shade", where the absolute amplitudes for $\mathrm{g}_{\mathrm{s}}$ 319 $\left(\mathrm{SA}_{\mathrm{gs}}\right)$ were highest for "Control", but lowest for "Drought". Although the SA were significantly 320different among treatments for both $\mathrm{A}$ and $\mathrm{g}_{\mathrm{s}}$, the relative amplitudes (RSA) were only significantly 321lower for the "Shade" treatment for both traits.

\subsection{Dynamic parameters of stomatal response under irradiance changes}

323During the closing sequence (from SS1 to SS2), the response time $(\tau)$ ranged from $\sim 90 \mathrm{~s}$ for the 324 faster responses to $\sim 600 \mathrm{~s}$ for the slowest (Table 2). Each treatment was significantly different from 325each other, with "Shade" (slowest) < "Control" < "Drought" (fastest). Interestingly, we only 326observed significantly different $\tau$ values between opening and closing sequence for the "Control" 327 treatment, with an asymmetrical response of $\sim 2$ times slower opening, whereas "Drought" and 328 "Shade" did not show a significantly asymmetric responses. 
330Table 1: Means per treatment ( \pm standard error of the mean) of net $\mathrm{CO}_{2}$ assimilation $\left(A_{\mathrm{n}}\right)$, stomatal 331conductance $\left(\mathrm{g}_{\mathrm{s}}\right)$, internal $\mathrm{CO}_{2}$ concentration $\left(\mathrm{C}_{\mathrm{i}}\right)$ at each steady-state reached during the 332measurement cycle (SS1-SS2-SS3, see Figure 1a for details). The amplitude of variation of the 333parameters between each steady state (SA and RSA, respectively in absolute values and 334percentage). For $C_{i}$, amplitude of variations was not shown as no differences between the steady 335states were observed. Different letters show the significant differences among treatments using a 336Tukey-HSD test. “*” represents the significant differences between two steady states from a paired 337 -test at $\mathrm{p}<0.05$. There were no significant differences between SS1 and SS3, which were therefore 338not indicated in the table.

\begin{tabular}{|c|c|c|c|c|c|c|c|c|}
\hline Treatments & & SS1 & & SS2 & & SS3 & SA & RSA (\%) \\
\hline Control & \multirow{3}{*}{$\begin{array}{c}A_{\mathrm{n}} \\
\left(\mu \mathrm{mol} \mathrm{m} \mathrm{m}^{-2} \mathrm{~s}^{-1}\right)\end{array}$} & $19.9 \pm 0.4^{a}(15)$ & $*$ & $4,7 \pm 0.4^{a}(16)$ & $*$ & $20.3 \pm 0.4^{a}(16)$ & $15.5 \pm 0.2^{\mathrm{a}}(15)$ & $77.0 \pm 1.6^{a}(15)$ \\
\hline Drought & & $11.1 \pm 0.5^{b}(18)$ & $*$ & $2.8 \pm 0.2^{b}(17)$ & $*$ & $12.1 \pm 0.7^{b}(17)$ & $8.9 \pm 0.7^{b}(17)$ & $75.2 \pm 2.9^{\mathrm{a}}(17)$ \\
\hline Shade & & $8.5 \pm 0.5^{c}(18)$ & $*$ & $3.7 \pm 0.2^{\mathrm{ab}}(18)$ & $*$ & $7.9 \pm 0.7^{c}(18)$ & $4.6 \pm 0.6^{c}(18)$ & $54.2 \pm 2.8^{b}(18)$ \\
\hline Control & \multirow{3}{*}{$\begin{array}{c}\mathrm{g}_{\mathrm{s}} \\
\left(\mathrm{mol} \mathrm{m}^{-2} \mathrm{~s}^{-1}\right)\end{array}$} & $0.41 \pm 0.03^{a}(15)$ & $*$ & $0.11 \pm 0.01^{\mathrm{a}}(16)$ & $*$ & $0.38 \pm 0.03^{\mathrm{a}}(16)$ & $0.28 \pm 0.02^{\mathrm{a}}(15)$ & $72.6 \pm 1.6^{a}(15)$ \\
\hline Drought & & $0.08 \pm 0.00^{c}(18)$ & $*$ & $0.02 \pm 0.01^{b}(17)$ & $*$ & $0.09 \pm 0.01^{c}(17)$ & $0.06 \pm 0.01^{c}(17)$ & $71.9 \pm 0.9^{a}(17)$ \\
\hline Shade & & $0.22 \pm 0.01^{b}(18)$ & $*$ & $0.1 \pm 0.01^{\mathrm{a}}(18)$ & $*$ & $0.2 \pm 0.01^{b}(18)$ & $0.11 \pm 0.01^{b}(18)$ & $54.2 \pm 2.4^{b}(18)$ \\
\hline Control & \multirow{3}{*}{$\begin{array}{c}\mathrm{Ci} \\
\left(\mu \mathrm{mol} \mathrm{mol}{ }^{-1}\right)\end{array}$} & $292.0 \pm 5.5^{b}(15)$ & ns & $312.5 \pm 9^{a}(16)$ & ns & $286.4 \pm 5.9^{\mathrm{a}}(16)$ & & \\
\hline Drought & & $160.3 \pm 11.9^{c}(18)$ & ns & $193.5 \pm 11^{b}(17)$ & ns & $159.7 \pm 15.9^{b}(17)$ & & \\
\hline Shade & & $320.3 \pm 4.4^{\mathrm{a}}(18)$ & ns & $323.5 \pm 4.1^{\mathrm{a}}(18)$ & ns & $316.0 \pm 7.7^{\mathrm{a}}(18)$ & & \\
\hline
\end{tabular}

339

340Table 2: Dynamic parameters for the opening and closing sequences, with $\tau$ the response time, $\lambda$ the 341delay of stomatal response, $\tau / \lambda$ their ratio and $\mathrm{SL}_{\max }$ the maximal slope of the response. Different 342letters show the significant differences between treatments from an ANOVA model including 343treatment effects followed by a post-hoc Tukey test. The number of analysed response curves are in 344parentheses, with a mean of 2.7 repetitions per leaf. * show the significant differences between 345 closing and opening from a paired t-test (P-values $<0.05$ ), so a significant difference indicates an 346asymmetric response.

\begin{tabular}{|c|c|c|c|c|c|}
\hline Treatment & & $\begin{array}{l}\text { Closing } \\
\text { SS1-Ss2 }\end{array}$ & & $\begin{array}{l}\text { Opening } \\
\text { SS2-SS3 }\end{array}$ & $\begin{array}{c}\text { Ratio } \\
\text { Closing/Opening }\end{array}$ \\
\hline Control & \multirow{3}{*}{$\begin{array}{c}\tau \\
(\mathrm{sec})\end{array}$} & $378 \pm 38^{a}(15)$ & $*$ & $695 \pm 118^{a}(16)$ & $0.59 \pm 0.04^{b}(15)$ \\
\hline Drought & & $87 \pm 4^{c}(18)$ & ns & $101 \pm 18^{\mathrm{b}}(17)$ & $1.09 \pm 0.16^{\mathrm{a}}(17)$ \\
\hline Shade & & $577 \pm 38^{b}(18)$ & ns & $637 \pm 52^{a}(18)$ & $0.92 \pm 0.06^{\mathrm{a}}(18)$ \\
\hline Control & \multirow{3}{*}{$\begin{array}{c}\lambda \\
(\mathrm{sec})\end{array}$} & $348 \pm 15^{\mathrm{a}}(15)$ & $*$ & $693 \pm 41^{\mathrm{a}}(16)$ & $0.51 \pm 0.01^{\mathrm{a}}(15)$ \\
\hline Drought & & $151 \pm 9^{c}(18)$ & $*$ & $430 \pm 81^{b}(17)$ & $0.39 \pm 0.03^{b}(17)$ \\
\hline Shade & & $278 \pm 16^{b}(18)$ & $*$ & $495 \pm 21^{b}(18)$ & $0.57 \pm 0.02^{a}(18)$ \\
\hline Control & \multirow{3}{*}{$\tau / \lambda$} & $1.08 \pm 0.08^{b}(15)$ & ns & $0.99 \pm 0.13^{\mathrm{a}}(16)$ & \\
\hline Drought & & $0.58 \pm 0.04^{c}(18)$ & $*$ & $0.25 \pm 0.05^{b}(17)$ & \\
\hline Shade & & $2.09 \pm 0.1^{a}(18)$ & $*$ & $1.3 \pm 0.12^{\mathrm{a}}(18)$ & \\
\hline Control & \multirow{3}{*}{$\begin{array}{c}\mathrm{SI}_{\max } \\
\left(\mathrm{mol} \mathrm{m} \mathrm{m}^{-2} \mathrm{~s}^{-2} \times 10^{5}\right)\end{array}$} & $-3.13 \pm 0.4^{b}(15)$ & $*$ & $1.79 \pm 0.16^{b}(16)$ & $-1.84 \pm 0.11^{b}(15)$ \\
\hline Drought & & $-3.16 \pm 0.3^{b}(18)$ & $*$ & $3.72 \pm 0.59^{a}(17)$ & $-0.97 \pm 0.11^{\mathrm{a}}(17)$ \\
\hline Shade & & $-0.96 \pm 0.1^{a}(18)$ & $*$ & $0.75 \pm 0.06^{b}(18)$ & $-1.33 \pm 0.06^{a}(18)$ \\
\hline
\end{tabular}


348The lag time of the response $(\lambda)$ showed a different pattern compared to $\tau$. During the closing 349sequence, "Drought" showed again the shortest delay (the fastest response, lowest $\lambda$ values), then 350 "Shade" treatment, then "Control" (the longest delay, highest $\lambda$ values). In all treatments, $\lambda$ was 351significantly higher for the opening than for the closing sequence (Table 2), with the strongest $\lambda$ 352asymmetry for the "Drought" treatment while the ratios were similar between "Shade" and 353 “Control” treatments.

354For the "Control" treatments, $\lambda$ and $\tau$ showed very similar values (ratio $\tau / \lambda \sim 1$ ) in both closing and 355opening sequences, for "Drought" and "Shade" treatments a significant deviation from unity was 356observed but in opposite directions: the "Drought" treatment induced a shift to a longer $\lambda$, whereas 357the "Shade" treatment induced a shift to higher $\tau$.

$358 \mathrm{SL}_{\max }$ for closing was significantly slower in the "Shade" treatment, whereas for opening it was 359significantly faster for the "Drought" treatment. This was due to the strong asymmetry observed for 360the "Control" treatment, which was much smaller in the "Drought" and "Shade" treatments.

361In Figure 2, the mean of the estimated parameters for each treatment was applied to the sigmoidal 362 model to visualize the differences in the responses, using a normalized $g_{s}$ scale (setting $g_{\min }$ to 0 and $363 \mathrm{~g}_{\max }$ to 1; Fig. 2a and Fig. 2b), as well as the measured $g_{s}$ values (Fig. 2c and 2d). Plants from the 364 "Drought" treatment reached the new steady state after the step-change in irradiance significantly 365 more rapidly compared to the other two treatments. As the normalized graphs do not depend on the 366amplitude, they illustrate the difference between the "Control" and "Drought" treatments in terms of $367 \tau$ and $\lambda$ : for a similar overall response time, the "Shade" treatment showed a shorter time lag of the 368response. 

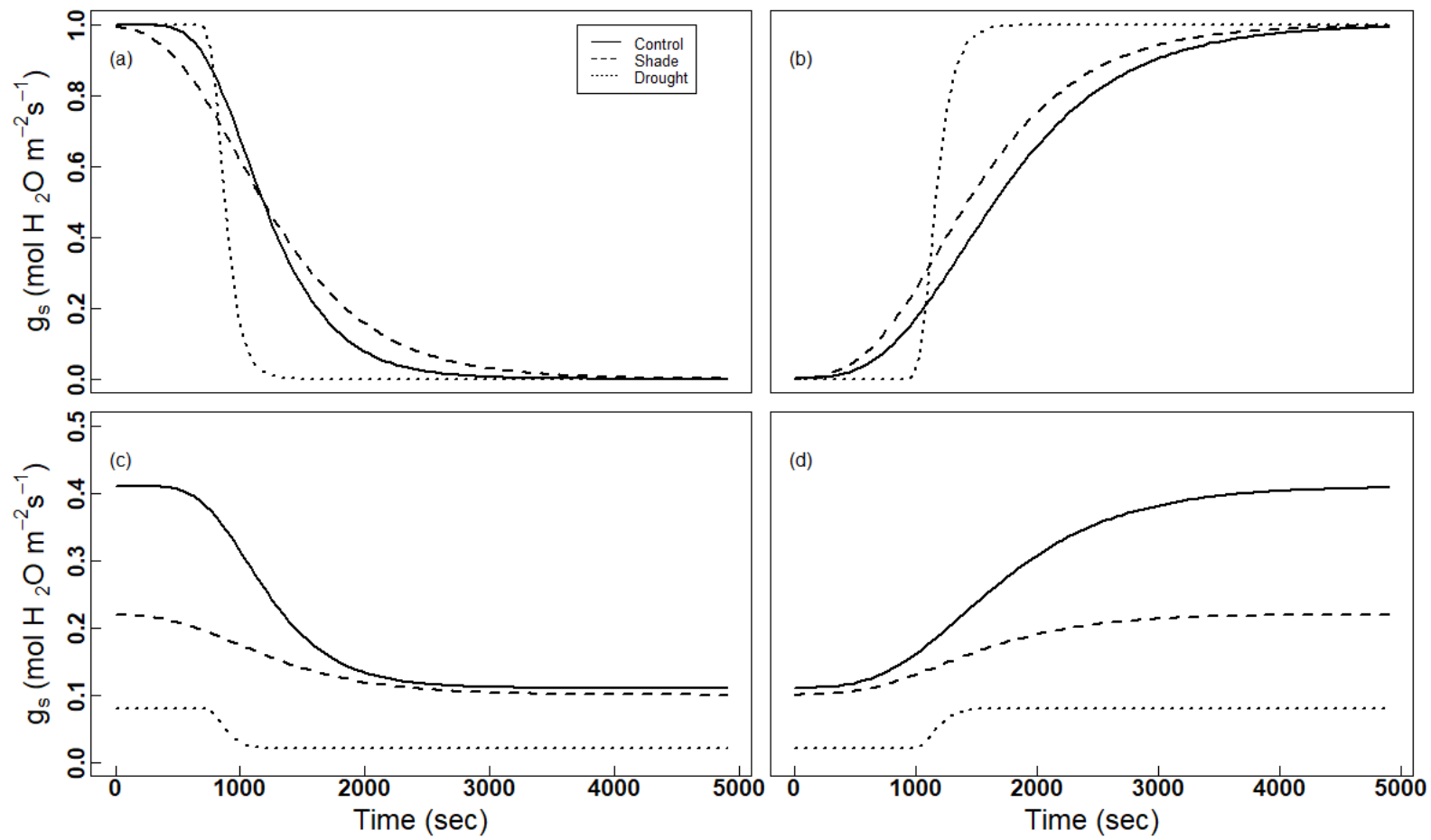

370

371Figure 2: Fitted stomatal dynamics induced by changes in light intensity in closing (a, c) and 372opening (b, d) sequences. Plain lines are for "Control", simple dashed lines for "Shade" and dotted 373lines for "Drought" treatment. Figures (a) and (b) show normalized conductance responses $\left(g_{\min }=0\right.$, $374 \mathrm{~g}_{\max }=1$ ), whereas measured values of $g_{\min }$ and $g_{\max }$ were used for Figures (c) and (d). Each curve 375 was estimated by using the mean values of the dynamic parameters from Table 2 and the sigmoidal 376model.

377

\subsection{Stomatal morphology in response of different treatments}

379No significant differences were found between abaxial and adaxial faces for the considered stomatal 380traits. Overall, the stomatal ratio abaxial/adaxial for the measured tobacco plants was $2.46 \pm 0.4$ 381 while the epidermal cell ratio was lower at $1.39 \pm 0.1$.

382Significantly lower SD and CD as well as SI values were observed for the "Shade" treatment (Table 3833), whereas no significant differences among treatments were observed for GCW, GSH and SS, 
385Table 3: Stomatal morphology means for treatments ( \pm standard error of the mean). GCL: guard cell 386length $(\mu \mathrm{m})$, GCW: pore width $(\mu \mathrm{m})$, SS: stomatal surface $\left(\mu \mathrm{m}^{2}\right)$, GSH: stomatal shape 387(GCL/GCW), SD: stomatal density $\left(\mathrm{mm}^{-2}\right), \mathrm{CD}$ : epidermis cell density $\left(\mathrm{mm}^{-2}\right)$, SI: stomatal index $388(\mathrm{SD} / \mathrm{SD}+\mathrm{CD})$. Different letters show the significant differences between the treatments (Tukey389HSD).

\begin{tabular}{|c|c|c|}
\hline Treatment & Trait & Mean $\pm S E(N)$ \\
\hline Control & \multirow{3}{*}{$\begin{array}{c}\mathrm{GCL} \\
(\mu \mathrm{m})\end{array}$} & $33.1 \pm 1.2^{\mathrm{a}}(5)$ \\
\hline Drought & & $35.1 \pm 1.7^{a}(5)$ \\
\hline Shade & & $34.0 \pm 0.5^{\mathrm{a}}(5)$ \\
\hline Control & \multirow{3}{*}{$\begin{array}{l}\text { GCW } \\
(\mu \mathrm{m})\end{array}$} & $26.7 \pm 0.8^{a}(5)$ \\
\hline Drought & & $26.4 \pm 0.8^{\mathrm{a}}(5)$ \\
\hline Shade & & $24.1 \pm 0.3^{a}(5)$ \\
\hline Control & \multirow{3}{*}{$\begin{array}{c}\text { SS } \\
\left(\mu \mathrm{m}^{2}\right)\end{array}$} & $695 \pm 55.2^{a}(5)$ \\
\hline Drought & & $731 \pm 73^{a}(5)$ \\
\hline Shade & & $666 \pm 22^{a}(5)$ \\
\hline Control & \multirow{3}{*}{ GSH } & $1.24 \pm 0.02^{\mathrm{b}}(5)$ \\
\hline Drought & & $1.33 \pm 0.03^{\mathrm{ab}}(5)$ \\
\hline Shade & & $1.41 \pm 0.02^{\mathrm{a}}(5)$ \\
\hline Control & \multirow{3}{*}{$\begin{array}{c}\mathrm{SD} \\
\left(\mathrm{mm}^{-2}\right)\end{array}$} & $126 \pm 7^{\mathrm{a}}(5)$ \\
\hline Drought & & $131 \pm 12^{\mathrm{a}}(5)$ \\
\hline Shade & & $58 \pm 8^{b}(5)$ \\
\hline Control & \multirow{3}{*}{$\begin{array}{c}C D \\
\left(\mathrm{~mm}^{-2}\right)\end{array}$} & $478 \pm 15^{\mathrm{a}}(5)$ \\
\hline Drought & & $544 \pm 73^{a}(5)$ \\
\hline Shade & & $318 \pm 25^{b}(5)$ \\
\hline Control & \multirow{3}{*}{ SI } & $0.2 \pm 0.01^{\mathrm{a}}(5)$ \\
\hline Drought & & $0.19 \pm 0.01^{\mathrm{a}}(5)$ \\
\hline Shade & & $0.15 \pm 0.01^{b}(5)$ \\
\hline
\end{tabular}


391Table 4. Correlation table of dynamic parameters and the stomatal morphology across treatments. The upper-right triangle displays the p-values (with

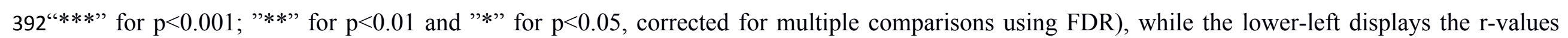
393(Pearson test). With the dynamic parameters: $\tau, \lambda, \mathrm{SL}_{\max }$ (where closing slopes are negative), their closing/opening ratio, the absolute amplitude of 394stomatal conductance response (SA), and the stomatal parameters: GCW (guard cells width), GCL (guard cells length), SS (stomatal size), SD 395(stomatal density), and SI (the stomatal index). $N=18$ for within dynamic parameter correlations and N=15 for correlations with morphology traits, bold 396r-values are highly significant $(* * *)$.

\begin{tabular}{|c|c|c|c|c|c|c|c|c|c|c|c|c|c|c|c|c|}
\hline & $\tau_{\mathrm{cl}}$ & $\tau_{\mathrm{op}}$ & $\lambda_{\mathrm{cl}}$ & $\lambda_{o p}$ & $\mathrm{Sl}_{\max \mathrm{cl}}$ & $S 1_{\text {max op }}$ & $\tau_{\text {ratio }}$ & $\lambda_{\text {ratio }}$ & $\mathrm{SL}_{\text {max ratio }}$ & $\mathrm{SA}_{\mathrm{cl}}$ & $\mathrm{SA}_{\mathrm{op}}$ & GCW & GCL & SS & SD & SI \\
\hline$\tau_{\mathrm{cl}}$ & & $* * *$ & $* *$ & & $* * *$ & $* * *$ & & $* *$ & & & & & & & $*$ & * \\
\hline$\tau_{\mathrm{op}}$ & 0.83 & & $* * *$ & $* * *$ & $*$ & $* * *$ & $* *$ & $*$ & $* * *$ & * & & & & & & \\
\hline$\lambda_{\mathrm{cl}}$ & 0.66 & 0.87 & & $* * *$ & & $*$ & $* *$ & $*$ & $* * *$ & $* *$ & $*$ & & & & & \\
\hline$\lambda_{\text {op }}$ & 0.46 & 0.75 & 0.9 & & & $*$ & ** & & $* * *$ & ** & $* *$ & & & & & \\
\hline $\mathrm{Sl}_{\max \mathrm{cl}}$ & 0.78 & 0.48 & & & & $* * *$ & & $*$ & & & & & & & $*$ & ** \\
\hline$S l_{\max o p}$ & -0.85 & -0.76 & -0.58 & -0.47 & -0.78 & & $*$ & & $*$ & & & & & & & \\
\hline$\tau_{\text {ratio }}$ & & -0.62 & -0.67 & -0.69 & & 0.55 & & & $* * *$ & & $* *$ & & & & & \\
\hline$\lambda_{\text {ratio }}$ & 0.68 & 0.51 & 0.48 & & 0.48 & -0.44 & & & & & & & & & & * \\
\hline $\mathrm{SL}_{\max \text { ratio }}$ & & -0.71 & -0.79 & -0.84 & & 0.54 & 0.83 & & & $* *$ & $* *$ & & & & & \\
\hline $\mathrm{SA}_{\mathrm{cl}}$ & & 0.59 & 0.84 & 0.85 & & & & & -0.77 & & $* * *$ & & & & & \\
\hline $\mathrm{SA}_{\mathrm{op}}$ & & & 0.77 & 0.82 & & & -0.69 & & 0.69 & 0.96 & & & & & & \\
\hline GCW & & & & & & & & & & & & & $* *$ & $* * *$ & & $*$ \\
\hline GCL & & & & & & & & & & & & 0.68 & & $* * *$ & & \\
\hline SS & & & & & & & & & & & & 0.9 & 0.93 & & & \\
\hline SD & -0.63 & & & & -0.64 & & & & & & & & & & & $* *$ \\
\hline SI & -0.52 & & & & -0.69 & & & -0.54 & & & & 0.64 & & 0.45 & 0.72 & \\
\hline
\end{tabular}


398The dynamic parameters $\tau, \lambda, \mathrm{SL}_{\max }$ and $\mathrm{SA}$ displayed significant and high correlations between 399their opening and closing values (Table 4). $\tau, \lambda$ and $\mathrm{SL}_{\max }$ also correlated with each other, especially 400within the same irradiance change sequences, except for $\lambda$ vs. $\mathrm{SL}_{\max }$ where the correlations were 401lower or not significant during opening and closing respectively. However, within the same 402sequence, $\mathrm{SA}$ did only correlate with $\lambda$ and not with $\tau$ or $\mathrm{SL}_{\max }$.

403There were no correlations between $\tau, \lambda, \mathrm{SL}_{\max }$, SA and the stomatal size parameters (GCW, GCL, 404SS). For closure, $\tau$ and $\mathrm{SL}_{\max }$ showed small negative correlations with $\mathrm{SD}$ and $\mathrm{SI}$ (Fig. 3), 405associating more stomata with faster responses. The $\tau$ relationships were more clearly driven by the 406treatments differences than the $\mathrm{SL}_{\max }$ relationships (Fig. 3). Whereas $\lambda$ did not correlate with 407stomatal size or density parameters, its asymmetry ( $\lambda$ ratio) correlated negatively with SI, 408expressing a tendency for the opening delay to be longer with more guard cells per total cells.
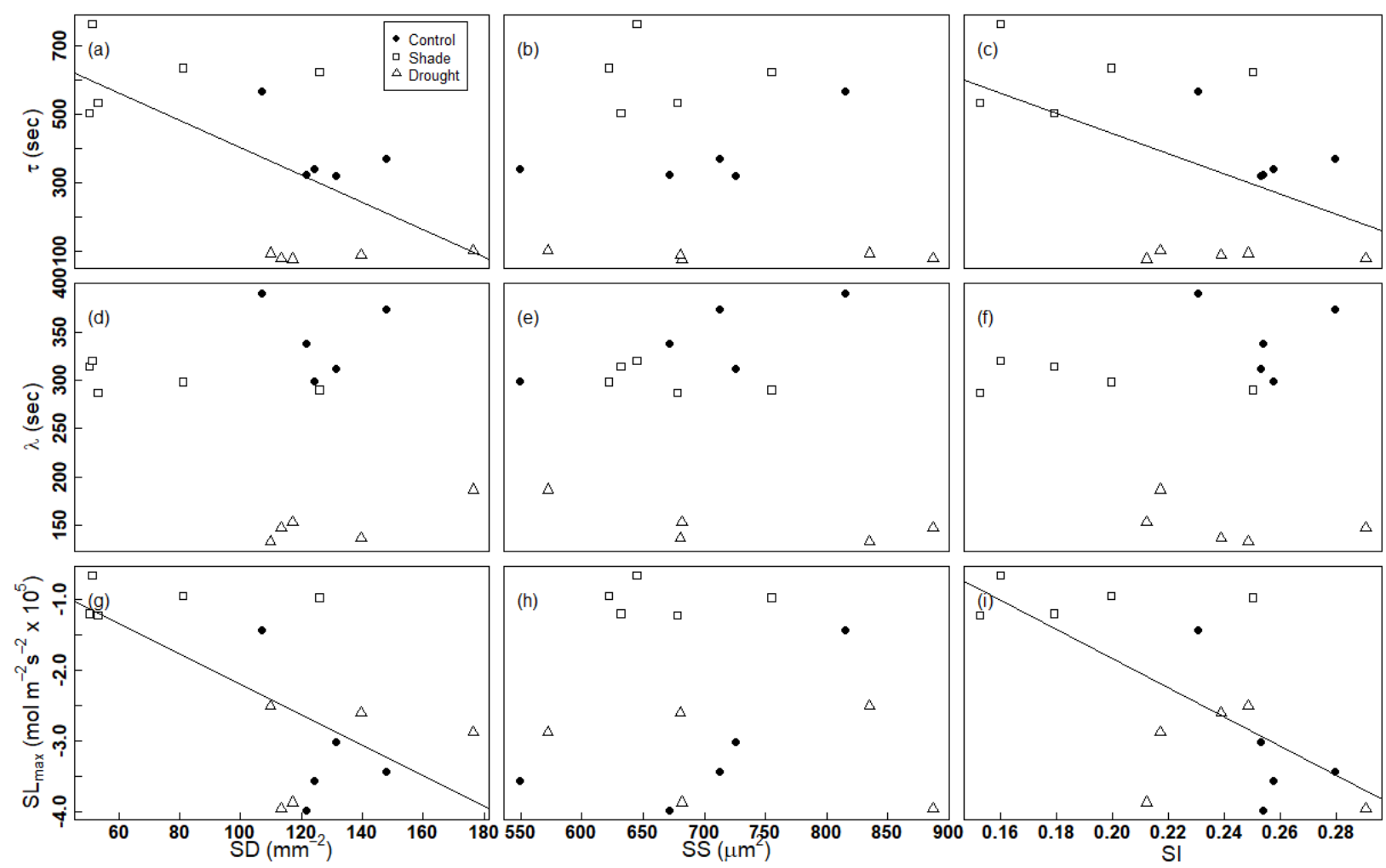

411Figure 3: Cross correlations between dynamic parameters of the closing sequences $(\tau$ - response 412time, $\lambda$ - lag time and $\mathrm{SL}_{\max }$ - maximum slope) and stomatal parameters (SS -stomatal size, SD 413stomatal density and SI -the stomatal index). Black dots for "Control", white squares for "Shade" 414and white triangles for "Drought" treatment. 


\section{Discussion}

\subsection{Treatments impact on steady states values}

418Under the high irradiance conditions of SS1 and SS3, both treatments reduced gs and A compared 419to control, where "Drought" had a stronger impact on gs and "Shade" a stronger impact on A. The 420latter is probably due to a reduced photosynthetic capacity for the plants of the "Shade" treatment 421(confirmed by unpublished data). Stomatal closure under drought is a well studied response 422(Turner, 1974; Tardieu and Davies, 1992; Giorio et al., 1999), whereas the stomatal closure under 423shade might be due to a $\mathrm{C}_{\mathrm{i}}$ mediated signal to optimize the leaf internal $\mathrm{CO}_{2}$ concentration (Mott, 4241988).

\subsection{Impact of the treatments on the dynamic response to irradiance}

426Kirschbaum et al. (1988) proposed a dynamic model in which the response to irradiance was 427hypothesized to be composed of three functional steps: first, a biochemical signal that responds 428directly to irradiance, then the subsequent variation of osmotic potential causing finally the 429movement of water, in/out the guard cells, inducing the actual stomatal movement. From our model 430we extracted two parameters ( $\tau$ and $\lambda$ ) both expressed as time constants, where $\lambda$ (as a lag time 431estimate) could be related to the time needed for the first biochemical signal induction, such as the 432phototropin I and II or zeaxanthin (Demming-Adams et al., 1989; Christie, 2007). Further, $\tau$, 433describing the steepness of the sigmoidal shape (Fig. 1b), could be related to the response time of 434the stomatal movement itself, which might be related to the ion and water fluxes operating during 435stomatal movements (Blatt, 2000).

436Similarly to the steady state parameters, the dynamic response to irradiance has been significantly 437changed by both treatments and resulted in contrasting stomatal behaviours in terms of opening and 438closing. For the "Control" treatment, the range values of $\tau, \lambda$ and $\mathrm{SL}_{\max }$ were comparable to a study 439on multiple species (including Nicotiana tabaccum) using a similar dynamic model and irradiance 440variations (McAusland et al., 2016). This study also showed a strong relationship between $\tau$ and $441 \mathrm{SL}_{\max }$ across species. The different treatments used in our study allowed a more detailed analysis of 442the overall coordination between lag and response times. The "Drought" treatment decreased lag $(\lambda)$ 443and response $(\tau)$ times for opening as well as closing, with a stronger impact on closing for $\lambda$, but a 444stronger impact on opening for $\tau$. No impact of drought was visible for $\mathrm{SL}_{\max }$ due to a simultaneous 445decrease in amplitude. It has been suggested that plants from drier climates or experiencing a 446drought stress showed similar faster responses (Vico et al., 2011; Lawson and Blatt, 2014). To the 447 best of our knowledge, only a few other studies have investigated experimental drought impact on 
448the dynamic of stomatal response (Qu et al., 2016; Haworth et al., 2018). Both studies observed 449faster responses associated to drought during stomatal closing, however, Haworth et al. (2018) 450 found no impact of drought on the opening sequence, which differs from our results. Therefore, 451literature results as well as our study seem to suggest an increase in stomatal speed under drought, 452however a conclusion on a differential impact between opening and closing will still need more 453experimental evidence. The coordinated response of the two time constants towards more rapid 454stomatal responses (reduced $\tau$ and $\lambda$ values) during drought suggest a tighter coupling between $A_{n}$ 455and $\mathrm{g}_{\mathrm{s}}$. This might reduce the loss of water, both at the instantaneous and long-term scale 456(McAusland et al. 2016) and thereby improve water use efficiency.

457To our knowledge, only few studies have estimated stomatal dynamics on experimental shade or 458low irradiance growth conditions (Kardiman and Raebild, 2017; Matthews et al., 2018). Our results 459on $\tau$ and $\mathrm{SL}_{\max }$ for closing tended to be in agreement with these previous studies in which shade 460grown plants displayed slower stomatal responses to irradiance, however for opening no differences 461to "Control" was shown. Similarly to the "Drought", also for the "Shade" treatment, the lag time $(\lambda)$ 462showed an acclimation in the opposite direction to a faster response. These results suggest that 463response $(\tau)$ and lag times $(\lambda)$ not only acclimated independently to the prevailing environmental 464treatments, but also that opening and closing mechanisms were not affected similarly by 465environmental conditions. Such differences between opening and closing response times $(\tau)$ might 466be partly due to the differential ion flux pathways involved in solute uptake and loss involved in 467stomatal opening and closing, respectively (Blatt, 2000; Shimazaki et al. 2007; Lawson and Blatt 4682014). Moreover, Haworth et al. (2018) have suggested that the free-ABA content might also have a 469large influence of the speed of stomatal movements. The acclimations observed for lag time might 470be more dependent on signalling pathways for irradiance signals (Blatt, 2000), but also via leaf 471internal $\mathrm{CO}_{2}$ concentration, modified by the irradiance impact on photosynthesis (Hiyama et al. 4722017).

473There was a strong asymmetry towards slower stomatal opening in the "Control" treatment for $474 \mathrm{SL}_{\max }$ as well as $\tau$ and $\lambda$. According to Woods and Turner (1971) an asymmetry in this direction 475might be an adaptation to reduce water loss as a fast stomatal closing allows a tighter coupling 476between $A_{n}$ and $\mathrm{g}_{\mathrm{s}}$ thus reducing excessive loss of water (Tinoco-Ojanguren and Pearcy, 1992; Ooba 477and Takahashi, 2003). A slower opening might also limit overshooting situations where stomata 478continue to open after an increase in irradiance, even when photosynthesis is saturated 479(MacAusland et al. 2016). However, no asymmetry was found for the "Drought" treatment 480concerning $\mathrm{SL}_{\max }$ and $\tau$, suggesting a stronger impact of "Drought" on the physiological 481mechanisms affecting the opening speed compared to "Control". Whereas for $\lambda$ the asymmetry was 
482even significantly stronger under drought, suggesting that the speed of the biochemical signalling of 483the irradiance change was more increased for closing, even if also the opening lag time was more 484rapid compared to control.

485Ooba and Takahashi (2003) suggested that light limited environments would favour a more rapid 486increase in $\mathrm{g}_{\mathrm{s}}$ as a faster stomatal opening would allow an improved coupling between $\mathrm{A}$ and $\mathrm{g}_{\mathrm{s}}$ and 487should theoretically increase the overall $\mathrm{CO}_{2}$ uptake. The experimental "Shade" treatment used here 488did increase the response time for closing relatively more than for opening, however this was not 489seen for $\mathrm{SL}_{\max }$, which was more reduced for closing. By dissecting the speed into several parameters 490as $\tau$, the response time (independent of amplitude), the amplitude itself and $\lambda$, the lag time, we were 491able to show that these parameters were affected differently, both "Drought" and "Shade" 492treatments equilibrated the response times between opening and closing, whereas the asymmetry of 493the lag time was significantly accentuated by the "Drought". This could suggest that irradiance 494response signalling pathways as well as physiological mechanisms relating to stomatal movements 495might be different between opening and closing and acclimate differently to environmental 496 constraints. However, to substantiate such a hypothesis, more detailed studies are necessary on the 497molecular level.

\subsection{Acclimation of stomatal morphology to drought and shade}

499Plants are known to adjust stomatal density, index and size during leaf development to the 500prevailing environmental conditions (Rawson and Craven, 1975; Carins Murphy et al., 2012; Kalve 501et al., 2014; McAusland et al., 2016). The decrease of stomatal density (SD) with increasing 502atmospheric $\mathrm{CO}_{2}$ concentration is well documented (Woodward, 1987; Pal et al., 2005; Franks and 503Beerling, 2009); however, there is no clear consensus about the impact of drought on stomatal 504morphology. Theodorou et al. (2013) observed antagonistic responses of SD among genotypes of 505grapevine cultivars submitted to drought. Similar contrasting results have been reported in tree 506(Laajimi et al., 2011) or grass species (Xu and Zhou, 2008). In this study, tobacco plants displayed 507 no acclimation to water deficit in terms of stomatal size, density or index, despite the high intensity 508of the water stress during the whole growing period, and thus the development of the measured 509leaves.

510Concerning shade growth conditions, most of the literature suggests a decrease of SD (Gay and 511Hurd, 1975; Brodribb and Jordan, 2011; Kardiman and Raebild, 2017; Matthews et al., 2018), 512linked to a lower stomatal index (SI) (Ashton and Berlyn, 1994, Sun et al., 2003; Aasamaa and 513Aphalo, 2016; Carins-Murphy et al., 2016;). This was also observed here, where the plants grown 514under shade displayed a significantly reduced SD, linked to a decrease in SI but no change of the 
515stomatal size, which corroborates the above cited literature results on woody and herbaceous 516species other than tobacco.

517

5184.4 Relationship between dynamic parameters and stomatal morphology

519Most of the studies on the relationships between stomatal morphology and dynamics report a faster 520stomatal response associated with smaller stomata or a higher stomatal density (Hetherington and 521Woodward 2003; Franks and Farquhar, 2007; Drake et al., 2013; Raven, 2014, Xiong et al., 2017). 522Nevertheless, other recent studies did not detect any significant correlation between stomatal 523density, size and the rapidity of response (Haworth et al., 2015; Aasamaa and Aphalo, 2016; Elliot524Kingston et al., 2016). Most of these studies focused on the inter-specific diversity while only one 525explored within species variation induced by an experimental shade (Aasama and Aphalo, 2016). In 526 all of these studies the rapidity of response was expressed as speed, which is $g_{s}$ variation over time. 527In our study we were able to decompose the speed of stomatal response $\left(\mathrm{SL}_{\max }\right)$ into several 528parameters ( $\tau$ and $\mathrm{SA}_{\mathrm{gs}}$ ), and showed that the similar $\mathrm{SL}_{\max }$ found in "Control" and "Drought" 529treatments resulted from significantly different response times $(\tau)$ and amplitudes of stomatal 530responses and therefore very different dynamic responses under these two treatments (Table 2). 531McAusland et al. (2016) have used a similar model and have found across species with elliptical 532shaped stomata that pore length correlated with speed ( $\mathrm{SL}_{\max }$, for opening only), probably related to 533the amplitude of the response (strong correlation with steady state $g_{s}$ ), but not with the response 534time $(\tau)$. In our study, within one species but across treatments, we did not find any correlation 535between dynamic parameters and guard cell length, width or surface, similarly to Aasama and 536Aphalo (2016). This result might be due to the relatively reduced variability of stomatal sizes within 537species, despite the range of environmental conditions. However, there were significant correlations 538between stomatal density or index and closing related parameters such as $\mathrm{SL}_{\max }$ and $\tau$. For the latter 539this was clearly a co-variation related to the differences among treatments, however for $\mathrm{SL}_{\max }$ this 540was less clear (Fig. 3) and might therefore suggest an effect of the number of stomata on stomatal 541closing speed, with more stomata resulting in faster dynamics. Such a more rapid stomatal response 542 with higher stomatal density had already been suggested for opening sequences by Vialet-Chabrand 543et al. (2016) using simulations. Finally, the observation of strong differences in stomatal dynamics 544 without (and not related to) a strong variation in stomatal size leads us to the conclusion that within545 species, acclimation of stomatal lag and response times involve other mechanisms than stomatal 546morphology. Such mechanisms could include physiological de-/activation of ion transport in the 547stomatal guard cells, or a genetic control on the expression of ion transport channels.

\section{Conclusion}


549In this study we highlighted the strong impact of "Drought" and "Shade" treatments on the dynamic 550response of stomata to variations in irradiance in tobacco plants. The rapidity of response was 551affected by both treatments but in different ways, where "Drought" reduced both the delay and 552response times (both faster), "Shade" treatment also reduced the delay but slowed the response 553time, thus significantly changing the shape and thus the dynamic of the response. Moreover, we 554showed different stomatal dynamics between closing and opening sequences among treatments, 555suggesting the existence of different signalling pathways and/or mechanisms involved in the 556asymmetrical response to irradiance in tobacco plants. However, these tests were only performed 557with one very large step-change in irradiance. An important perspective would be to confirm the 558coherence of these results with step-changes of different amplitudes and different starting 559irradiances.

560The impact of the "Shade" treatment on the stomatal dynamics could be an indication that when 561introducing such dynamics into canopy scale models, a different parametrization between sun and 562shade leaves might have to be taken into account. To gain a more mechanistic insight into the 563acclimation of stomatal dynamics to the growth environment, a more molecular approach would be 564necessary to observe short-term variations of guard-cell gene expression, ion channel functioning or 565abundance.

\section{Declaration of interest}

567All authors disclose any financial or personal conflict of interest.

\section{Author contributions}

570TG, CD, OB designed the experiment, CD and JF provided study material and environment, TG 571and $\mathrm{CD}$ conducted the experiment, TG, $\mathrm{CD}, \mathrm{OB}$ did the data analysis, and $\mathrm{TG}, \mathrm{CD}, \mathrm{OB}$, JF wrote 572the manuscript and were involved in the interpretation and critical discussion of the results, OB and 573JF obtained funding.

\section{4}

\section{Acknowledgement}

576TG acknowledges the $\mathrm{PhD}$ grant from the H20ak ANR-14-CE02-0013 project. The research stay 577of TG was supported by a grant overseen by the French National Research Agency (ANR) as part 578of the "Investissements d'Avenir" program (ANR-11-LABX-0002-01, Lab of Excellence ARBRE) 579and financial support of INRA / DARESE. JF and CD acknowledge funding from the MINECO 580project CTM2014-53902-C2-1-P. 


\section{Literature}

582Aasamaa, K., Sõber A., 2011. Responses of stomatal conductance to simultaneous changes in two 583environmental factors. Tree Physiol. 31, 855-864

584

585Aasamaa, K., Aphalo, PJ., 2016. The acclimation of Tilia cordata stomatal opening in response to light, and 586stomatal anatomy to vegetational shade and its components. Tree Physiol. 37, 209-219

587

588Ashton, P.M.S., Berlyn, G.P., 1994. A comparison of leaf physiology and anatomy of Quercus (section

589Erythrobalanus-Fagaceae) species in different light environments. Am J Bot. 81, 589-597

590

591Blatt, M.R., 2000. Cellular signalling and volume control in stomatal movements in plants. Annu Rev Cell 592Dev Biol. 16, 221-241

593

594Brodribb, T.J., Jordan, G.J., 2011. Water supply and demand remain balanced during leaf acclimation of 595Nothofagus cunninhamii trees. New Phytol. 192, 437-448

596

597Carins Murphy, M.R., Jordan, G.J., Brodribb, T.J., 2012. Differential leaf expansion can enable hydraulic 598acclimation to sun and shade. Plant, Cell \& Environ. 35, 1407-1418

599

600Carins Murphy, M.R, Jordan, G.J., Brodribb, T.J., 2016. Cell expansion not cell differentiation 601 predominantly co-ordinates veins and stomata within and among herbs and woody angiosperms grown under 602 sun and shade. Annals of Bot. 118, 1127-1138

603

604Casson, S., Gray, J.E., 2008. Influence of environmental factors on stomatal development.. New Phytol. 178, 6059-23

606

607Christie, J.M., 2007. Phototropin blue-light receptors. Annu Rev Plant Biol. 58, 21-45

608

609Clifford, S.C., Black, C.R., Robert, J.A., Stronach, I.M., Singleton-Jones, P.R., Mohamed, A.D., Azam-Ali, 610S.N., 1995. The effect of elevated atmospheric $\mathrm{CO}_{2}$ and drought on stomatal frequency in groundnut 611(Arachis hypogaea (L.)). J Exp Bot. 46, 847-852

612

613Demming-Adams, B., Winter, K., Kruger, A., Czygan, F.C., 1989. Light Response of $\mathrm{CO}_{2}$ Assimilation, 614Dissipation of Excess Excitation Energy, and Zeaxanthin Content of Sun and Shade Leaves. Plant Physiol. $61590,881-886$

616

617Doheny-Adams, T., Hunt, L., Franks, P.J., Beerling, D.J., Gray, J.E., 2012. Genetic manipulation of stomatal 618density influences stomatal size, plant growth and tolerance to restricted water supply across a growth carbon 619dioxide gradient. Philos Trans R Soc Lond B Biol Sci. 367, 547-555

620

621Dow, G.J., Berry, J.A., Bergmann, D.C., 2014.The physiological importance of developmental mechanisms 622that enforce proper stomatal spacing in Arabidopsis thaliana. New Phytol. 201, 1205-1217

623

624Drake, P.L., Froend, R.H., Franks, PJ., 2013. Smaller, faster stomata: scaling of stomatal size, rate of 625response, and stomatal conductance. J Exp Bot. 64, 495-505

626

627Elliot-Kingston, C., Haworth, M., Yearsley, J.M., Batke, SP., Lawson, T., McElwain, J.C., 2016. Does Size 628Matter? Atmospheric $\mathrm{CO}_{2}$ May Be A Stronger Driver of Stomatal Closing Rate Than Stomatal Size in Taxa 629That Diversified under Low $\mathrm{CO}_{2}$. Front Plant Sci. 7, 1253

630

631Franks, P.J., Beerling, D.J., 2009. Maximum leaf conductance driven by $\mathrm{CO}_{2}$ effects on stomatal size and 632density over geologic time. Proc Natl Acad Sci USA. 106, 10343-10347

633

634Franks, P.J., Doheny-Adams, T., Britton-Harper, Z.J. and Gray, J.E., 2015. Increasing water-use efficiency 635directly through genetic manipulation of stomatal density. New Phytol. 207, 188-195

636 
637Franks, P.J, Farquhar, G.D., 2007. The mechanical diversity of stomata and its significance in gas-exchange 638control. Plant Physiol. 143, 78-87

639

640Gay, A.P., Hurd, R.G., 1975. The influence of light on stomatal density in the tomato. New Phytol. 75, 3764146

642

643Giorio, P., Sorrentino, G., d'Andria, R., 1999. Stomatal behavior, leaf water status and photosynthetic 644response in field-grown olive trees under water deficit. Env Exp Bot. 42, 95-104

645

646Haworth, M., Killi, D., Materassi, A., Raschi, A., 2015. Coordination of stomatal physiological behaviour 647and morphology with carbon dioxide determines stomatal control. Am J Bot. 102, 677-688

648

649Haworth, M., Marino, G., Cosentino, S. L., Brunetti, C., De Carlo, A., Avola, G., . \& Centritto, M., 2018.

650Increased free abscisic acid during drought enhances stomatal sensitivity and modifies stomatal behaviour in 651fast growing giant reed (Arundo donax L.). Environ Exp Bot. 147, 116-124.

652

653Hetherington, A.M., Woodward, F.I., 2003. The role of stomata in sensing and driving environmental 654change. Nature 424, 901-908

655

656Hiyama, A., Takemiya, A., Munemasa, S., Okuma, E., Sugiyama, N., Tada, Y,Murata, Y., Shimazaki, K.I., 6572017. Blue light and $\mathrm{CO}_{2}$ signals converge to regulate light-induced stomatal opening Nat Commun. 8, 1284

658

659Jones, H.G., 1977. Transpiration in barley lines with differing stomatal frequencies. J Exp Bot 28, 162-168

660

661Kardiman, R., Ræbild, A., 2017. Relationship between stomatal density, size and speed of opening in 662Sumatran rainforest species, Tree Physiol. 1-10

663

664Kaiser, E., Morales, A. and Harbinson, J., 2018. Fluctuating light takes crop photosynthesis on a

665rollercoaster ride. Plant Physiol. 176, 977-989.

666Kalve, S., Fotschki, J., Beeckman, T., Vissenberg, K., Beemster, G.T.S., 2014. Three-dimensional patterns of 667cell division and expansion throughout the development of Arabidopsis thaliana leaves. J Ex Bot. 65, 63856686397

669

670Kirschbaum, M.U.F., Gross, L.J., Pearcy, R.W., 1988. Observed and modelled stomatal responses to 671dynamic light environments in the shade plant Alocasia macrorrhiza. Plant Cell Environ. 11, 111-121

672

673Laajimi, N.O., Boussadia, O.,Skhiri, F.H., Teixeira da Silva, J.A., Rezgui, S., Hellali, R., 2011. Anatomical 674adaptations in vegetative structures of Apricot tree (Prunus armeniaca L.) cv. 'Amor El Euch' grown under 675 water stress. Fruit, Vegetable and Cereal Sci. Biotech. 5, 46-51

676

677Lawson, T., Blatt, M.R., 2014. Stomatal size, speed, and responsiveness impact on photosynthesis and water 678use efficiency. Plant Physiol. 164, 1556-1570

679

680Lawson, T., Morison, J.I.L., 2004. Stomatal function and physiology. In AR Hemsley, I Poole, eds, The 681Evolution of Plant Physiology; from whole plants to ecosystem. Elsevier, Amsterdam, pp. 217-242

682

683Lawson, T., von Caemmerer, S., Baroli, I., 2010. Photosynthesis and stomatal behaviour. In UE Lüttge, W 684Beyschlag, B Büdel, D Francis, eds, Progress in Botany. Springer, Berlin, pp. 265-304

685

686Martins, S.C., McAdam, S.A., Deans, R.M., DaMatta, F.M. and Brodribb, T.J., 2016. Stomatal dynamics are 687limited by leaf hydraulics in ferns and conifers: results from simultaneous measurements of liquid and 688vapour fluxes in leaves. Plant Cell Environ. 39, 694-705

689

690Matthews, J.S., Vialet-Chabrand, S.R. and Lawson, T., 2018. Acclimation to fluctuating light impacts the 691rapidity and diurnal rhythm of stomatal conductance. Plant Physiol. 176, 1939-1951

692 
693McAusland, L., Vialet-Chabrand, S., Davey, P., Baker, N.R., Brendel, O., Lawson, T., 2016. Effects of 694kinetics of light-induced stomatal responses on photosynthesis and water-use efficiency. New Phytol. 211, 6951209-1220

696

697Merilo, E., Laanemets, K., Hu, H., Xue, S., Jakobson, L., Tulva, I., Gonzalez-Guzman, M., Rodriguez, P.L., 698Schroeder, J.I., Broschè, M., Kollist, H., 2013. PYR/RCAR Receptors Contribute to Ozone-, Reduced Air 699Humidity-, Darkness-, and $\mathrm{CO}_{2}$-Induced Stomatal Regulation. Plant Physiol. 162, 1652-1668

700

701Mott, K.A., 1988. Do Stomata Respond to $\mathrm{CO}_{2}$ Concentrations Other Than Intercellular. Plant Physiol. 86, 702200-203

703

704Ooba, M., Takahashi, H., 2003. Effect of asymmetric stomatal response on gas-exchange dynamics. Ecol 705Modell. 164, 65-82

706

707Outlaw, W.H., 2003. Integration of cellular and physiological functions of guard cells. CRC Crit Rev Plant 708Sci. 22, 503-529

709

710Pal, M., Rao, L.S., Jain, V., Srivastava, A.C., Pandey, R., Raj, A., Singh, K.P., 2005. Effects of elevated $\mathrm{CO}_{2}$ 711and nitrogen on wheat growth and photosynthesis. Biolo. Plantarum. 49, 467-470

712

713Pearcy, R.W., Schulze, E.D., Zimmermann, R., 2000. Measurement of transpiration and leaf conductance. In 714Plant Physiological Ecology, pp. 137-160. Springer, Dordrecht.

715

716Qu, M., Hamdani, S., Li, W., Wang, S., Tang, J., Chen, Z., Song, Q., Li, M., Zhao, H., Chang, T., 2016 717Rapid stomatal response to fluctuating light: an under-explored mechanism to improve drought tolerance in 718rice. Funct. Plant Biol. 43, 727-738

719

720Raven, J.A., 2014. Speedy small stomata? J Exp Bot. 65, 1415-1424

721

722Rawson, H., Craven, C., 1975. Stomatal development during leaf expansion in to- bacco and sunflower. Aust 723J Bot. 23, 253-261

724

725Schindelin, J.; Rueden, C. T., Hiner, M. C., Eliceiri K.W., 2015. The ImageJ ecosystem: An open platform

726for biomedical image analysisis. Mol Rep Dev. 82, 518-529

727

728Schlüter, U., Muschak, M., Berger, D., Altmann, T., 2003. Photosynthetic performance of an Arabidopsis 729mutant ith elevated stomatal density (sdd1-1) under different light regimes. J Exp Bot. 54, 867-874

730

731Schulze, E.D., Hall, A.E., 1982. Stomatal responses, water loss and $\mathrm{CO}_{2}$ assimilation rates of plants in 732contrasting environments. In Physiological Plant Ecology II, pp. 181-230. Springer, Berlin, Heidelberg.

733

734Shimazaki, K.I., Doi, M., Assmann, S., Kinoshita, T., 2007. Light Regulation of Stomatal Movement. Annu 735Rev Plant Biol. 58, 219-247

736

737Sun, B., Dilcher D.L., Beerling D.J., Zhang C., Yan D., Kowalski E., 2003. Variation in Ginkgo biloba L.

738leaf characters across a climatic gradient in China. Proc Natl Acad Sci USA. 100, 7141-7146

739

740Tardieu, F., Davies, W.J., 1992. Stomatal response to abscisic acid is a function of current plant water status. 741Plant Physiol. 98, 540-545

742

743Team, R. C., 2015. R Foundation for Statistical Computing; Vienna, Austria: 2014. R: A language and 744environment for statistical computing, 2013.

745

746Theodorou, N., Koundouras, S., Zioziou, E., \& Nikolaou, N., 2013. Responses of leaf stomatal density and 747 anatomy to water deficit in four winegrape cultivars (Vitis vinifera L.). AMPELOS $2013-3^{\text {rd }}$ international 748symposium on trends in world vitiviniculture development conference; 30-31 May 2013 Santorini island, 749 Greece 
751Thomas, P.W., Woodward, F.I., Quick, W.P., 2004. Systemic irradiance signaling in tobacco. New Phytol. 752161, 193-198

753

754Tinoco-Ojanguren, C, Pearcy, R.W., 1992. Dynamic stomatal behavior and its role in carbon gain during 755lightflecks of a gap phase and an understory Piper species acclimated to high and low light. Oecologia. 92, 756222-228

757

758Turner, N.C., 1974. Stomatal behavior and water status of maize, sorghum, and tobacco under field 759conditions II. At low soil water potential. Plant Physiol. 53, 360-365

760

761Tuteja, N., 2007. Abscisic Acid and Abiotic Stress Signaling. Plant Signal Behav. 2, 135-138

762

763Vico, G., Manzoni, S., Palmroth, S., Katul, G., 2011. Effects of stomatal delays on the economics of leaf gas 764exchange under intermittent light regimes. New Phytol. 192, 640-652

765

766Vialet-Chabrand, S., Dreyer, E., Brendel, O., 2013. Performance of a new dynamic model for predicting 767diurnal time courses of stomatal conductance at the leaf level. Plant Cell Environ. 36, 1529-1546

768

769Vialet-Chabrand, S., Matthews, J.S.A., Brendel, O., Blatt, M.R., Wang, Y., Hills, A., Griffiths, H., Rogers, S. 770and Lawson, T., 2016. Modelling water use efficiency in a dynamic environment: an example using 771Arabidopsis thaliana. Plant Science. 251, 65-74

772

773Vialet-Chabrand, S.R.M., Matthews, J.S.A., McAusland, L., Blatt, M.R., Griffiths, H., Lawson, T., 2017. 774Temporal Dynamics of Stomatal Behavior: Modeling and Implications for Photosynthesis and Water Use. 775Plant Physiol. 174, 603-613

776

777Woods, D.B., Turner, N.C., 1971. Stomatal response to changing light by four tree species of varying shade 778tolerance. New Phytol. 70, 77-84

779

780Woodward, F.I., 1987. Stomatal numbers are sensitive to increases in $\mathrm{CO}_{2}$ from pre-industrial 781levels. Nature. 327, 617-618

782

783Xiong, D., Douthe, C., Flexas, J., 2017. Differential coordination of stomatal conductance, mesophyll 784conductance and leaf hyraulic conductance in response to changing light across species. Plant Cell Environ. 78541, 436-450

786

787Xu, Z., Zhou, G., 2008. Responses of leaf stomatal density to water status and its relationship with 788photosynthesis in a grass. J Exp Bot 59, 3317-3325 